\title{
Exploratory and confirmatory molecular approaches to determine genetically modified status in different crops
}

\author{
Hanaa Abdel-Sadek Oraby* (1), Nadia Aboul-Ftooh Aboul-Maaty and Hayam Ahmad Al-Sharawi
}

\begin{abstract}
Background: One of the parameters required for the assessment of food and feed safety is detection and identification of genetically modified organisms. Legislation in some countries necessitates detection and quantification of modification in food and feed samples. Scientists have raised concern about safety of antibiotic resistance marker (ARM) genes used for transformation of crops intended for human and animal consumption. In the present work two molecular approaches have been adopted: one exploratory; for detection and quantification of ARM genes in tested plant samples and the other confirmatory; to determine the specificity/reliability of the obtained results.

Results: Results revealed that primers for neomycin phosphotransferase (npt/l) and aminoglycoside 3" adenyltransferase (aadA) were amplified in the majority of the 36 DNA screened samples. Melting curve analysis using hygromycin phosphotransferase (aph/M) gene as target sequence for the fluorescent-based detection approach was performed to ensure reliability and specificity of this procedure and to confirm results obtained by using conventional polymerase chain reaction (PCR). Quantitative RT-PCR results and validation analysis followed, revealed that all of the tested DNA samples were not violating the European legislation for GMOs labeling (0.9\%).

Conclusions: The results fully demonstrated the reproducibility, sensitivity/specificity of the adopted approaches for detection and quantification of even traces of GMO contents. Applying measurement uncertainty (MU) procedures presented in this work will help decision makers to ensure compliance with International Legislation and Regulations. This in its turn will facilitate and enhance trading with countries having compelling labeling regulations.
\end{abstract}

Keywords: Genetically modified organisms, GM crops, PCR, Melting curve, RT-PCR, Measurement uncertainty

\section{Background}

The technology of genetically modified organisms (GMOs) is mainly directed toward increasing the yield of a particular crop by introducing resistance to herbicides, insect pests, and certain diseases or by improving storage, transport, and harvest characteristics (James 1999; Mathur et al. 2017). The genetic composition of a GMO is usually altered by insertion of a piece of DNA having a desired trait into the genome of a recipient organism. This process called transformation. A typical insert in a

*Correspondence: haoraby@gmail.com

Department of Cell Biology, Genetic Engineering and Biotechnology

Research Division, National Research Centre, Cairo, Egypt
GMO is composed of a promoter to start signaling, the gene of interest, and a terminator to stop signaling. Several other elements are used in a gene construct; as antibiotic resistance marker genes to confirm the presence of genetic modification. The use of antibiotic resistance marker genes in the development of GMOs has raised concern worldwide about the safety of these genes in GM crops intended for human and animal consumption, which highlighted the increased demand for reliable and accurate analytical methods for detection and quantification of GM products (Mafra et al. 2008).

Legislation in some countries requires traceability, detection and quantification of GMOs to comply with labeling regulations for products that contain GMOs 
above a certain threshold (Cankar et al. 2008). Strict EU regulations necessitate detection and quantification of GM events in food and feed samples. Regulations also necessitate estimation of the measurement uncertainty that originates during analytical section of the detection procedure.

Monitoring of GMOs is considered an important procedure in assessing the level of safety in the release of GMOs into the environment. Several approaches have been developed to detect GM food or feed applying protein-based techniques, RNA- and DNA- based techniques (Salisu et al. 2017) to search for the inserted foreign protein or gene. One of the latest developed protein-based technique (Zenga et al. 2021) is the colloidal gold immune chromatographic strip (ICS) which is used for simultaneous detection of multiple transgenic proteins. The DNA-based approaches, on the other hand, are considered the methods of choice, DNA-based methods rely on the inherent stability of its double stranded structure and the possibility of multiplying it using the polymerase chain reaction (PCR) technology (Anklam et al. 2001).

This work employed three of the DNA-based molecular techniques; the conventional polymerase chain reaction (PCR), the fluorescent-based detection technique (Farrar and Wittwer 2017) using real time-PCR and a fluorogenic TaqMan probe specific for $n p t I I$ for detection and quantification of GM-crops.

Conventional PCR (C-PCR) was applied first for screening plant crops and animal feed for the presence of genetic modifications using two pairs of primers for Cauliflower Mosaic Virus promoter; P-35S and GT88. It was also applied to investigate the presence of the antibiotic resistance marker genes; neomycin phosphotransferase (nptII), and aminoglycoside 3 " adenyl-transferase $(\operatorname{aad} A)$.

The hygromycin phosphotransferase (aphIV) antibiotic resistance marker gene was also used as target sequence for the fluorescent-based detection assay. Melting curve analysis was performed to ensure accuracy and specificity of the procedures and results.

Quantitative evaluation of genetic modification was carried out using the real-time polymerase chain reaction (RT-PCR) with TaqMan probe specific for $n p t I I$ gene (101 bp-target) in presence of a standard reference material (CRM from Fluka).

Measurement uncertainty (MU) values were estimated in order to judge whether the analytical results exceeded a threshold or not. The MU values were estimated following the Guidance Document on Measurement Uncertainty for GMO Testing Laboratories (Trapmann et al. 2009), and further reported along with the measurement results.

\section{Methods}

Thirty two plant crops and four animal feed samples were purchased from different plant seed and animal feed suppliers. Plant crops were packaged in tins where identification particulars were provided. These purchased plant crops were imported from nine different countries distributed in Europe, United States of America (USA), and Asia where were produced. None of the purchased plants or animal feed was labeled as genetically modified.

\section{Sampling and DNA extraction}

Homogenous samples were prepared by milling approximately $100-250 \mathrm{~g}$ of starting material in a grinding food machine. One gram of each sample was further grounded to fine powder by the help of liquid nitrogen. DNA was extracted in duplicate from all samples applying a modified CTAB-based method (Aboul-Maaty and Oraby 2019).

\section{Qualitative detection for genetic modification}

For screening purposes, we employed two molecular procedures for qualitative detection methods. The first based on the use of conventional PCR and the second was a Fluorescent-based detection approach using real timePCR (Farrar and Wittwer 2017).

\section{Conventional PCR approach (C-PCR)}

Detection of the presence of genetic modification was performed using two pairs of primers to amplify two segments from CaMV promoter; P-35S (195 bp-target) and GT88 (88 bp-target) using C-PCR. Two other pairs of primers (nptII and aadA) were synthesized to amplify segments from $n p t I I$ gene (173 bp-target) and aadA gene (284 bp-target) respectively. Sequences, annealing temperatures and amplicon lengths of primers used during this study are presented in Table 1.

Amplifications were carried out in a total volume of $25 \mu$ reaction mixture which contained $100 \mathrm{ng}$ template DNA, $2 \mathrm{mM} \mathrm{MgCl}, 50 \mathrm{mMKCl}, 200 \mu \mathrm{M}$ of each dNTP, 2.5 pmol of each primer and 2.5 units of taq DNA polymerase in a reaction buffer $(75 \mathrm{mM}$ Tris- $\mathrm{HCl}, \mathrm{pH}$ 8.0, $50 \mathrm{mM} \mathrm{KCl}, 20 \mathrm{mM}\left(\mathrm{NH}_{4}\right)_{2} \mathrm{SO}_{4}$, and $\left.0.001 \% \mathrm{BSA}\right)$. All Polymerase Chain Reactions were conducted at least in duplicates and accomplished in TM Thermal cycler (MJ Research PTC-100 thermocycler) programmed to perform an initial denaturation step of $95^{\circ} \mathrm{C}$ for $2 \mathrm{~min}$, followed by 40 cycles consisting of $30 \mathrm{~s}$ at $95^{\circ} \mathrm{C}$ for denaturation, $45 \mathrm{~s}$ at annealing temperature for each primer (Table 1), and $30 \mathrm{~s}$ at $72{ }^{\circ} \mathrm{C}$ for extension. A final extension step of $7 \mathrm{~min}$ at $72{ }^{\circ} \mathrm{C}$ was performed. Following completion of the cycling reaction, $2 \mu \mathrm{l}$ of a tracing dye $(1 \mu \mathrm{g} / \mathrm{ml}$ ethidium bromide) was added to $10 \mu \mathrm{l}$ of each reaction product and separated by $2 \%$ agarose gel 
Table 1 List of primers employed for detection and quantification of GMOs, Primers positions ${ }^{\mathrm{a}}$ on the genomes, sequences, amplicon lengths and annealing temperatures

\begin{tabular}{|c|c|c|c|c|c|}
\hline Primers & Positions on the genomes ${ }^{a}$ & Sequences $\left(5^{\prime}-3^{\prime}\right)$ & $\begin{array}{l}\text { Amplicon } \\
\text { length (bp) }\end{array}$ & $\begin{array}{l}\text { Annealing } \\
\text { temp. }\left({ }^{\circ} \mathrm{C}\right)\end{array}$ & References \\
\hline \multirow[t]{2}{*}{ P-35S } & $7190-7209$ & 5'-GCTCCTACAAATGCCATCA-3' & 195 & 57 & Hemmer (1997) \\
\hline & $7364-7384$ & 5'-GATAGTGGGATTGTGCGTCA-3' & & & \\
\hline \multirow[t]{2}{*}{ GT88 } & $7117-7138$ & 5'-TCCGGAAACCTCCTCGGATTCCAT-3' & 88 & 54 & Oraby et al. (2014) \\
\hline & $7183-7206$ & 5'-GGCATTTGTAGGAGCCACCTTCCT-3' & & & \\
\hline \multirow[t]{2}{*}{ nptll } & $2382-2397$ & 5'-GGATCTCCTGTCATCT-3' & 173 & 50 & Hemmer (1997) \\
\hline & $2539-2554$ & 5'-GATCATCCTGATCGAC-3' & & & \\
\hline \multirow[t]{3}{*}{ nptll } & $2145-2167$ & 5'-CTATGACTGGGCACAACAGACA-3' & 101 & 60 & Cited by Li et al. (2015) \\
\hline & $2225-2245$ & 5'-CGGACAGGTCGGTCTTGACA-3' & & & \\
\hline & Probe: $2172-2195$ & FAM-CTGCTCTGATGCCGCCGTGTTCCG-TAMRA & & & \\
\hline \multirow[t]{2}{*}{ aphIV } & $14,025-14,044$ & 5'-CCGATTCCGGAAGTGCTTGA-3' & 649 & 60.5 & Designed for this work \\
\hline & $14,654-14,673$ & $5^{\prime}-$ CCCAAGCTGCATCATCGAAA-3' & & & \\
\hline \multirow[t]{2}{*}{$\operatorname{aad} A$} & $1188-1208$ & 5'-CGC TAT GTT CTC TTG CTT TTG-3' & 284 & 63 & Hollingshead and Vapnek (1985) \\
\hline & $1451-1471$ & 5'-TGA TTT GCT GGTTAC GGT GAC-3' & & & \\
\hline
\end{tabular}

a Primers positions relevant to: Cauliflower mosaic virus genome (accession no. emb|V00141.1|), nptll gene (accession no. AF080390.1), aphIV gene (accession no. KY080693.1) and aadA gene (accession no. MH973510.1)

electrophoresis and analyzed using SYNGENE Bio Imaging Gel Documentation System for the presence of a fluorescent band of the expected level for each primer.

\section{Fluorescent-based detection approach}

The fluorescent-based detection approach was performed using the real time-PCR (RT-PCR) in presence of $10 \mu \mathrm{l}$ Maxima SYBR Green qPCR master mix and $1 \mu$ of each forward and reverse DNA primers specially designed for the amplification of a segment of aphIV gene which was used as screening target for the presence of genetic modifications. Template DNA (150 ng of each sample) was added and the reaction volume was adjusted by DEPC water to a final volume of $20 \mu \mathrm{l}$. Amplification was started with initial denaturation at $95{ }^{\circ} \mathrm{C}$ for $15 \mathrm{~min}$, followed by 40 cycles of denaturation at $94{ }^{\circ} \mathrm{C}$ for $15 \mathrm{~s}$, annealing at $60{ }^{\circ} \mathrm{C}$ for $30 \mathrm{~s}$, and extension at $72{ }^{\circ} \mathrm{C}$ for $30 \mathrm{~s}$. Fluorescence measurements were obtained during the elongation step with SYBR Green1 dye. Additionally a final step for melting curve analysis was performed to ensure accuracy and specificity of the results.

\section{Quantification of genetic modification in plant samples Standard curve construction}

Taq Man probe for nptII gene (101 bp-target) was synthesized by Applied Biosystem, UK (Table 1) to determine the percentage of $n p t I I$ gene in selected plant seeds and feeds samples. Quantification of genetic modification in selected samples was determined in relation to a constructed standard curve from different dilutions (0.1,
0.5 and $5 \%$ ) from the certified reference material (CRM; Fluka) using nptII gene (101 bp-target).

DNA templates were, prepared from the different dilutions of the certified reference standard material (CRM) following the standardized CTAB-based protocol (Aboul-Maaty and Oraby 2019). The standard curve was generated by blotting the log of the initial template GM percentages against the threshold cycle $(\mathrm{Ct})$ generated for each concentration. Comparing the $\mathrm{Ct}$ values of the unknown samples to the standard curve allows the quantification of initial GM concentration percent for each sample. Real time-PCR was performed with the DNA of tested plant samples along with the DNA of different Fluka standard concentrations.

\section{TaqMan RT-PCR conditions and amplification}

Reaction mixture was prepared in $12.5 \mu \mathrm{l}$ master mix (TaqMan Universal PCR Master Mix, ABI), $300 \mathrm{nM}$ of each primer, $200 \mu \mathrm{M}$ probe and $100 \mathrm{ng}$ DNA. The final volume $(25 \mu \mathrm{l})$ was adjusted by nuclease-free water. The quantitative real-time PCR analysis was carried out in an RT-PCR Cycler-Rotor-Gene Q 2 Plex-with 2 channels (QIAGEN) and data analyzed by the software version Rotor-Gene 2.0.2.4. RT-PCR amplification profile started by a hold step for $15 \mathrm{~min}$ at $95^{\circ} \mathrm{C}$ followed by 40 repeats of $15 \mathrm{~s}$ at $94{ }^{\circ} \mathrm{C}$ and $60 \mathrm{~s}$ at $60^{\circ} \mathrm{C}$.

\section{Estimation of measurement uncertainty relevant to GMO quantification}

Data obtained from quantification of genetic modification in plant samples using TaqMan probe RT-PCR 
were used for estimation of Measurement Uncertainty involved in the GMO analysis following the Guidance Document on Measurement Uncertainty for GMO Testing Laboratories (Trapmann et al. 2009). This approach also evaluates the parameters involved in the analysis that may cause uncertainty about the reproducibility of the results.

\section{Results}

Conventional polymerase chain reaction (PCR) approach Results indicated that four of the collected plant samples gave no amplification with all investigated primers. These four plant samples are: yellow maize (Benicia variety from Ireland), and samples for Lupine, Vicia faba, and wheat from Egypt.

According to results in Table 2 primers specific for $35 S$ promoter (195 bp-target) and GT88 were amplified in most of the screened plant samples (Figs. 1 and 2 respectively). The percentage of the presence of the two components (P-35S and GT88) of CaMVP35S promoter together in the same samples was $80.5 \%$ of the screened samples. On the other hand, the GT88 (88 bp-target) fragment was separately identified in two samples; soybean (20) and golden rice (30). Primers for the nptII (173 bp-target) and aadA (284 bp-target) were amplified in $72.2 \%$ and $61.1 \%$ respectively of the DNA of the investigated samples (Table 2).

Collected plant crop and animal feed samples were also screened for the presence of antibiotic resistance marker genes; $n p t I I$ gene, and aadA gene. Primers for the nptII (173 bp-target) were amplified in $71.87 \%$ of the collected plant samples and in $75 \%$ of the collected animal diets (Fig. 3).

\section{Fluorescent-based detection approach for investigating the presence of $a p h I V$ gene qualitatively using real time-PCR}

Figure 4 represents amplification plot (panel A) and melting curve (panel B) obtained by the fluorescentbased detection approach with SYBR Green I dye for the selected DNA samples. Analysis of the targets containing the third antibiotic resistance marker gene (aphIV gene) are listed in Table 3 . The gathered information of the dissociation of double-stranded DNA amplicon of tested samples during heating (Fig. 4 panel B) showed that the peak detection of melting temperatures $\left(T_{\mathrm{m}}\right)$ ranged from 81.5 to $82.5{ }^{\circ} \mathrm{C}$ in all tested samples (Table 3) denoting positive amplification of the aphIV gene primers.

\section{Quantitative detection of $n p t / l$ gene in GM-crops applying TaqMan probe technology}

The constructed standard curve (Fig. 5) from Fluka CRM dilutions (0.5, 2 and 5) using specific Taq Man Probe for
nptII gene (101 bp target) demonstrated that the correlation co-efficient $\left(R^{2}\right)$ value was equal to 0.999 and the reaction efficiency was equal to $92 \%$, whereas the slope was -3.526 . The limit of quantification (LOQ) was $0.49 \%$ as presented in Table 4.

The exact percent of the target sequence in some of the tested samples with unknown concentrations were further quantified against the constructed Fluka standard curve and presented in Table 5. The calculated mean concentration percent in five of the tested samples $(6,9$, 13,19 and 35) recorded higher values $(1.088,3.680,1.92$, $1.437,2.95$ respectively) than that of the permissible GM\% (0.9\%).

\section{Estimation of measurement uncertainty parameters involved in the GMO quantification.}

In order to evaluate the performance of the method employed in the present work (Table 5); different uncertainty parameters involved in the GMO quantification were further estimated.

The absolute difference $\left(\Delta_{\mathrm{m}}=\left|C_{\mathrm{m}}-C_{\mathrm{CRM}}\right|\right)$ between mean measured results and certified value $\left(C_{\mathrm{CRM}}=0.9\right)$ was compared with the expanded uncertainty $\left(U_{\Delta}=k\right.$ - $u_{\Delta}$ ) of the difference between our results and certified value. In the present work the calculated absolute difference $\left(\Delta_{\mathrm{m}}\right)$ of each of the tested samples was smaller than the corresponding $U_{\Delta}$ (expanded uncertainty) of the same sample. These results denoted that there was no significant difference between the measurement result and the certified value. Based on that the difference between the reported GM concentrations and the expanded uncertainty $\left(U_{\Delta}\right)$ value for all samples were calculated (Table 5). Results indicated that none of the tested plants DNA samples exceeded the permissible concentration threshold $(0.9 \%)$.

\section{Discussion}

During this work we adopted two approaches: one exploratory; to investigate the presence of genetic modification in tested plant samples and the other confirmatory to determine the specificity and reliability of the obtained results.

For the purpose of screening GM crops the conventional PCR assay was employed. The universal primers for Cauliflower mosaic virus promoter (P-35S; $195 \mathrm{bp})$ were successfully amplified in most of the tested samples (Table 2). Generally, fragments of the frequently used promoter or terminator are used for the detection of genetically modified plants (Duijn et al. 1999; Kok et al. 2000; Oraby et al. 2005). Twenty four different regions on the CaMV Promoter were previously reported (Wu et al. 2014) as detection methods for GMOs. Primers for GT88 segment (Oraby et al. 2014) used in the present work is 
Table 2 Detected genetic modifications in some of the collected plant samples using primers for P-35S (195 bp), GT 88 (88 bp), nptll (173 bp) and aadA1 (284 bp)

\begin{tabular}{|c|c|c|c|c|c|c|}
\hline Code number & Samples & Genus species & P-35S (195 bp) & GT88 (88 bp) & NPTII (173 bp) & aadA (284 bp) \\
\hline 1 & Yellow maize (Benicia) & Zea mays & - & - & - & - \\
\hline 2 & Yellow corn & Zea mays & + & + & + & + \\
\hline 3 & Potato 1 & $\begin{array}{l}\text { Solanum tubero- } \\
\text { sum }\end{array}$ & + & + & + & + \\
\hline 4 & Potato 2 & $\begin{array}{l}\text { Solanum tubero- } \\
\text { sum }\end{array}$ & + & + & + & + \\
\hline 5 & Potato 3 & $\begin{array}{l}\text { Solanum tubero- } \\
\text { sum }\end{array}$ & + & + & + & - \\
\hline 6 & Potato 4 & $\begin{array}{l}\text { Solanum tubero- } \\
\text { sum }\end{array}$ & + & + & + & + \\
\hline 7 & Potato 5 & $\begin{array}{l}\text { Solanum tubero- } \\
\text { sum }\end{array}$ & + & + & + & + \\
\hline 8 & Potato 6 & $\begin{array}{l}\text { Solanum tubero- } \\
\text { sum }\end{array}$ & + & + & + & + \\
\hline 9 & Water melon & Citrullus lanatus & + & + & + & + \\
\hline 10 & Tomato & $\begin{array}{l}\text { Solanum lycoper- } \\
\text { sicum }\end{array}$ & + & + & + & + \\
\hline 11 & Tomato & $\begin{array}{l}\text { Solanum lycoper- } \\
\text { sicum }\end{array}$ & + & + & + & - \\
\hline 12 & Melon & Cucumis melo & + & + & + & + \\
\hline 13 & Squash & $\begin{array}{l}\text { Cucurbitales } \\
\text { maxima }\end{array}$ & + & + & + & - \\
\hline 14 & Cucumber & Cucumis sativus & + & + & + & - \\
\hline 15 & Cucumber & Cucumis sativus & + & + & + & + \\
\hline 16 & Cucumber & Cucumis sativus & + & + & - & - \\
\hline 17 & Lupine & Lupinus Lupinus & - & - & - & - \\
\hline 18 & Chick-pea & Cicer arientinium & + & + & - & + \\
\hline 19 & French bean & $\begin{array}{l}\text { Phaseolus } \\
\text { vulgaris }\end{array}$ & + & + & - & + \\
\hline 20 & Soybean & Vicia faba & - & + & + & - \\
\hline 21 & Faba & Lens culinaris & - & - & - & - \\
\hline 22 & Lentil & Glycine max & + & + & + & + \\
\hline 23 & Sweet pepper & $\begin{array}{l}\text { Capsicum } \\
\text { annuum }\end{array}$ & + & + & + & + \\
\hline 24 & Sweet pepper & $\begin{array}{l}\text { Capsicum } \\
\text { annuum }\end{array}$ & + & + & + & + \\
\hline 25 & Cabbage & Brassica oleracea & + & + & + & - \\
\hline 26 & Berenjena & $\begin{array}{l}\text { Solanum melon- } \\
\text { gena }\end{array}$ & + & + & + & - \\
\hline 27 & Berenjena romy & $\begin{array}{l}\text { Solanum melon- } \\
\text { gena }\end{array}$ & + & + & + & - \\
\hline 28 & Wheat (Romania) & Triticum aestivum & + & + & + & + \\
\hline 29 & Wheat & Triticum aestivum & - & - & - & - \\
\hline 30 & Golden rice & Oryza sativa & - & + & - & - \\
\hline 31 & Thai rice & Oryza sativa & + & + & + & + \\
\hline 32 & Cotton & $\begin{array}{l}\text { Gossypium } \\
\text { arboreum }\end{array}$ & + & + & - & + \\
\hline 33 & Animal diet1 B (Cairo) & & + & + & + & + \\
\hline 34 & Animal diet 2 R (FMx) & & + & + & - & + \\
\hline 35 & Animal diet 3 (rodent) & & + & + & + & + \\
\hline 36 & Animal diet 4 B (FMX) & & + & + & + & + \\
\hline
\end{tabular}




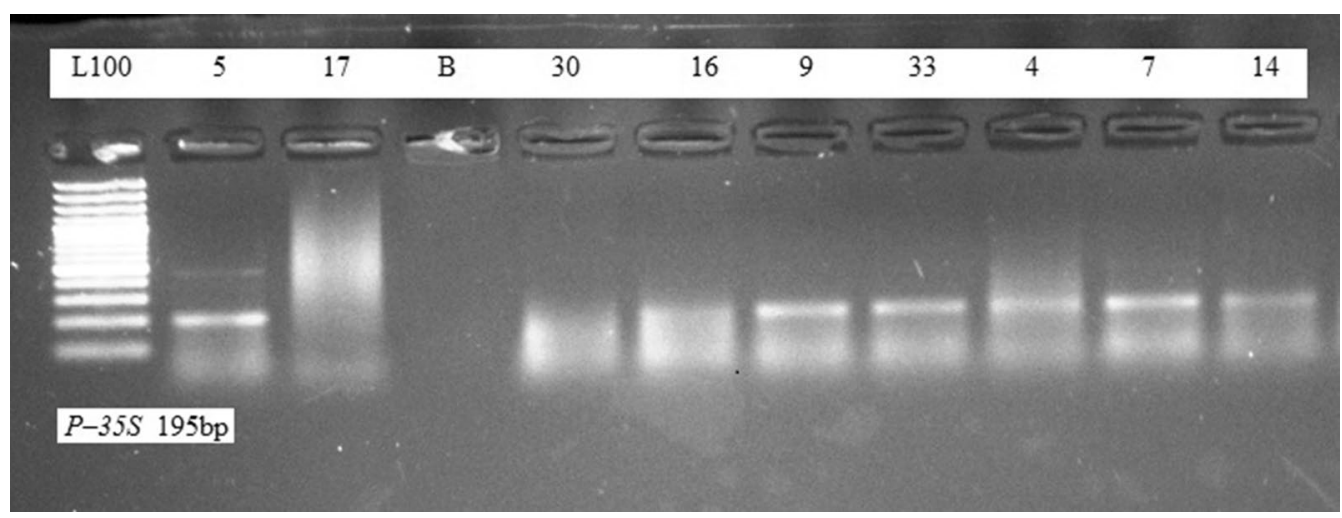

Fig. 1 Selected PCR amplification products of $P$-35S (195 bp) in some of the collected plant and animal feed samples. B is blank

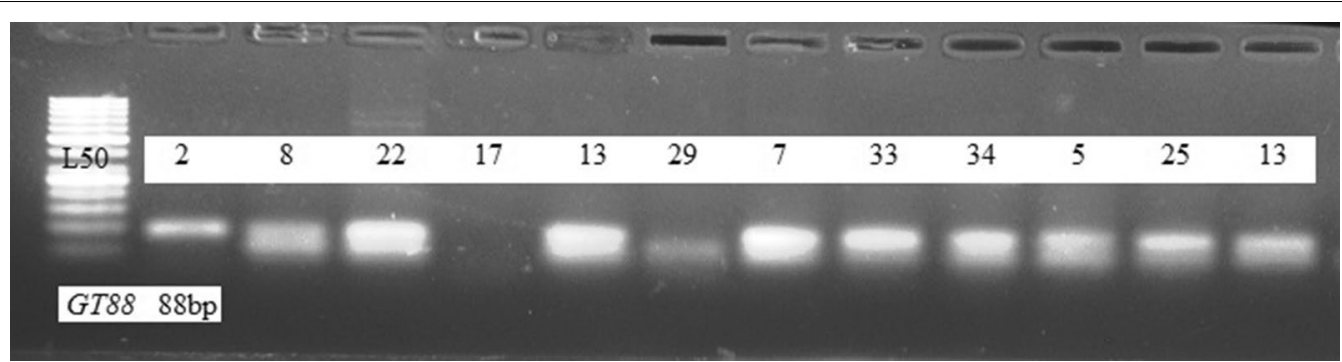

Fig. 2 Selected PCR amplification products of GT88 (88 bp) in some of the collected plant samples

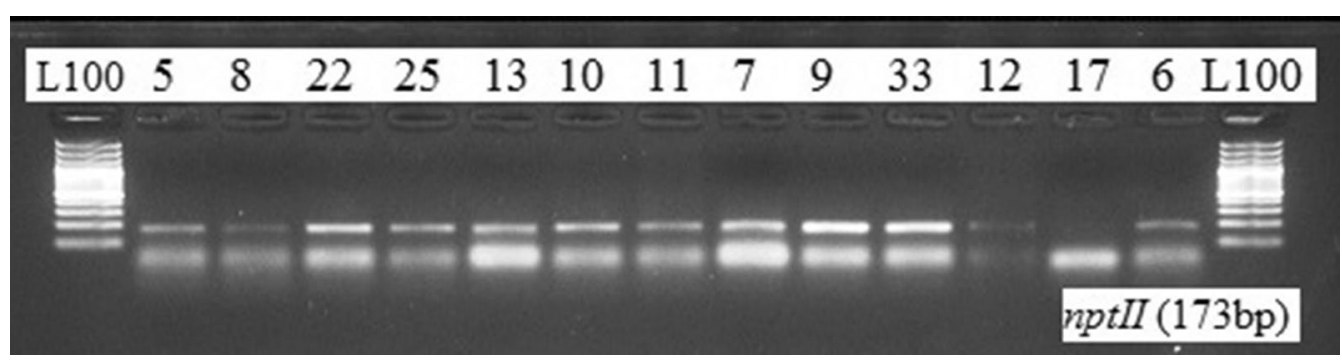

Fig. 3 Selected PCR amplification products of nptll (173 bp) in some of the collected plant samples. Sample 33 is for one of the tested animal feed

targeting a new region (7117-7206) on the CaMV P-35S promoter (accession no. emb|V00141.1|). This new set of primers (GT88) was amplified in $86.1 \%$ of the collected samples, whereas $P$-35S (195 bp) was amplified in $83.3 \%$. Amplification results of GT88, in the present work not only supported the presence of $C a M V-35 S$ promoter in these samples, but also suggested the use of these primers as an additional method for screening GMOs since it is targeting a new region in the $C a M V-35 S$ promoter.

The conventional PCR assay was also applied for exploring the presence of fragments from antibiotic resistance marker genes; nptII (173 bp) and aadA
$(284 \mathrm{bp})$ in the collected plant samples. Primers for $n p t I I$ and $\operatorname{aad} A$ were successfully amplified in $72.2 \%$ and $61.1 \%$ respectively of the collected samples. Fragments from both genes were detected together in $50 \%$ of the screened samples.

GM plants usually contain bacterial antibiotic resistance (AR) genes which are used as selectable marker genes in the early laboratory stages during their development. The bacterial aadA gene, coding for aminoglycoside $3^{\prime \prime}$ adenyl transferase, is under the control by its own bacterial promote (Miki and McHugh 2004) which renders it inactive in plants thus it is not expressed in 


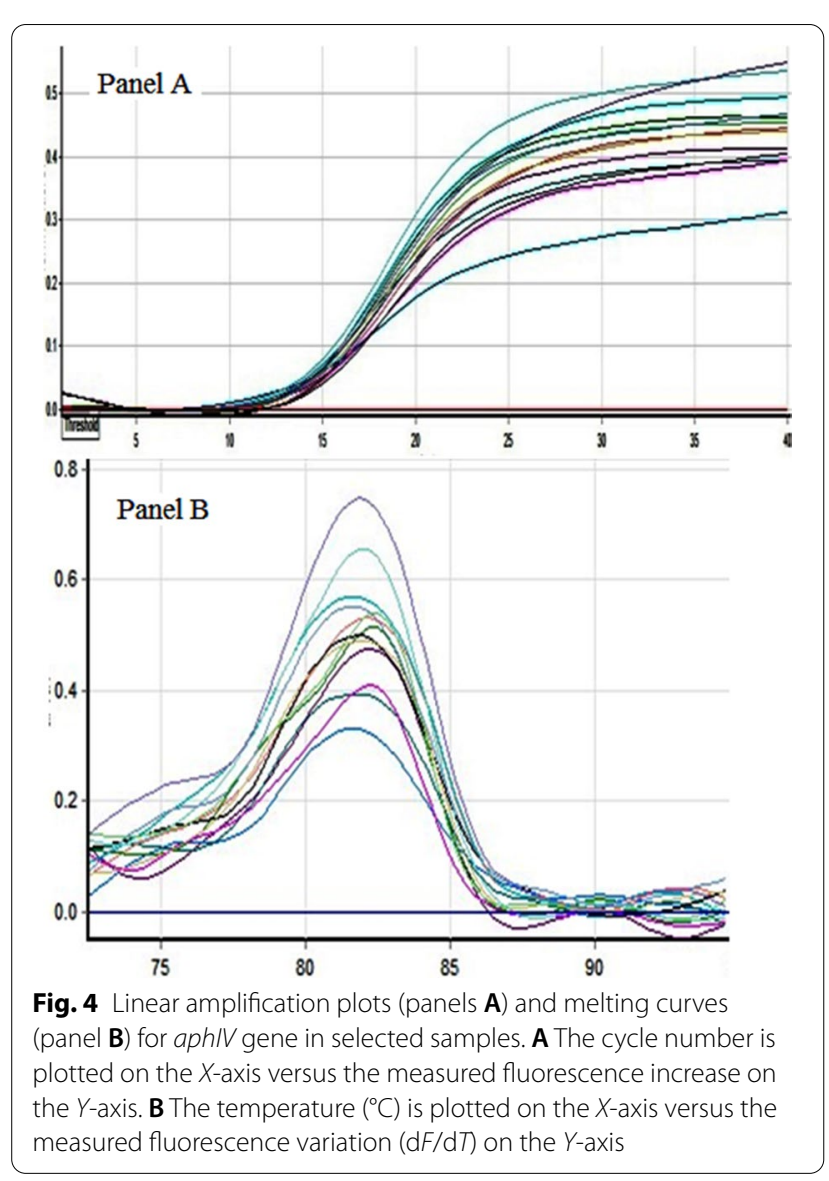

Table 3 Melt curve analysis: rate of changes of fluorescence due to amplicon dissociation of aphIV in tested samples and peak detection range data

\begin{tabular}{lll}
\hline Plant samples & $\begin{array}{l}\text { Melting } \\
\text { temperatures } \\
\left(\boldsymbol{T}_{\mathbf{m}}\right)\end{array}$ \\
\hline Code & Name & $\begin{array}{l}\text { peak } \\
\text { detection } \\
\text { range data } \\
\left({ }^{\circ} \mathbf{C}\right)\end{array}$ \\
\hline Level 4 & Fluka CRM 1\% & 82.2 \\
12 & Melon & 82.0 \\
14 & Cucumber/Hybrid Assel/France & 82.0 \\
16 & Cucumber/Hybrid beit alpha/USA & 82.3 \\
20 & Soybean/Egypt & 82.0 \\
24 & Sweet pepper/Moaz/USA & 82.2 \\
25 & Cabbage & 81.5 \\
28 & Wheat/Romania & 81.8 \\
30 & Golden rice/Thailand & 81.7 \\
31 & Jasmine rice/Thailand & 81.7 \\
32 & Cotton/Egypt & 82.0 \\
35 & Animal diet/NRC/Egypt & 81.5 \\
36 & Animal diet 4B (FMX) & 82.5 \\
\hline
\end{tabular}

GM plants. The nptII gene on the other hand has mostly been used as selectable marker genes (Vidhya et al. 2012) under the control of plant promoter in transgenic plants. For more efficient selection methods, nptII in some cases is used in combination with aminoglycoside phosphotransferase gene rather than using it alone (Kumar et al. 2004; Tabatabaei et al. 2017). This was confirmed in our work where the presence of both genes (nptII and aphIV) was detected in some of the investigated samples when applying the conventional-PCR and the fluorescentbased detection approaches.

Some authors (Miki and McHugh 2004) reported that such markers are routinely eliminated prior to plant transformation. They claimed that markers conferring resistance to hygromycin or other antibiotics have been used in plant research (Day 2003), but do not appear in GM-plants. Our results showed evidence for the presence of these ARM genes in most of the screened plant and diet samples. Adugna and Mesfin (2008) also used nptII gene as screening element for detection and quantification of GM crops. In addition, presence of nptII was reported in transgenic pigeon pea plants (Surekha et al. 2005) and transgenic cotton samples (Vidhya et al. 2012). It has also been reported that nptII gene was used for the production of most citrus transgenic plants (Ballester et al. 2008).

To overcome the limitation of detection of GMOs using conventional PCR the fluorescent-based detection approach using a DNA binding dye (SYBR green 1) in presence of aphIV primers as target sequence was also implemented as a confirmatory approach for detection of GMOs. This approach was followed by the melt curve analysis to estimate the specificity of the amplified products based on their melting characteristics of the double stranded DNA (dsDNA) during heating (Farrar and Wittwer 2017). Due to its dependence upon the length of the product and the type of its nucleotides component this assay allowed for the differentiation between the target specific amplicon and any non-specific amplicons (Nolan et al. 2013). The gathered information presented in Table 3 showed that primers for aphIV were positively amplified in all selected samples. These results reflect the importance of applying this assay as a complementary approach to the conventional PCR for the detection of GM plants since, screening results using the conventional PCR approach showed that some of the plant samples (14, $16,20,25,30$ and 32 ) were found to be negative to one or more of the other investigated primers (Table 2). These results also supported the suggestion of Anklam et al. (2001) that the absence of one or two of the screening elements in tested plant samples do not signify that these samples are not modified, it rather 


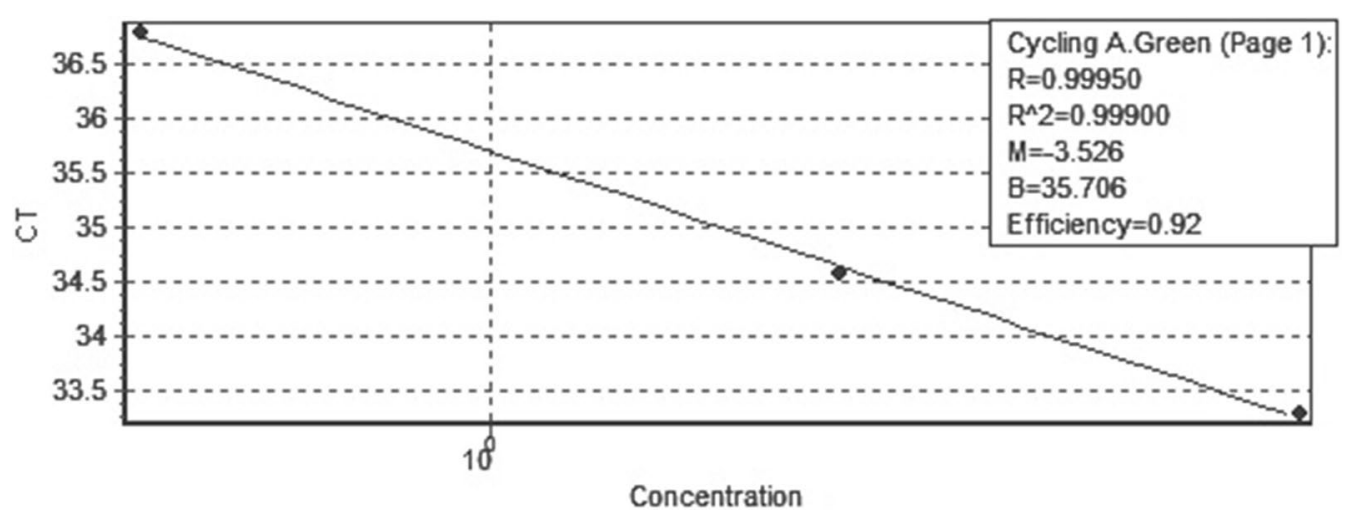

Fig. 5 Standard curve generated from Fluka CRM dilutions $(0.5,2,5)$ using Taq Man Probe

Table 4 Calculated initial concentration percent for the standard curve constructed from different dilutions from the Fluka CRM

\begin{tabular}{lllll}
\hline Code & Type & Ct & Given conc (\%) & Calc conc (\%) \\
\hline 1 & Standard & 37.07 & 0.500000 & 0.490130 \\
2 & Standard & 34.81 & 2.000000 & 2.102754 \\
3 & Standard & 33.51 & 5.000000 & 4.851434 \\
\hline
\end{tabular}

recommends using more than one primer for screening plant samples for the presence of genetic modification. As it is well known that no one method can detect all commercially available transgenic events (Wu et al. 2014) due to the different methods used for the construction of plant transformation. In the present work using different DNA-based methods for screening the

Table 5 Measurement Uncertainty using the value of within-laboratory measurement variation

\begin{tabular}{|c|c|c|c|c|c|c|c|c|c|}
\hline \multirow{2}{*}{$\begin{array}{l}\text { Sample } \\
\text { number }\end{array}$} & \multicolumn{3}{|c|}{ Calculated concentration $\%$} & \multirow[t]{2}{*}{$\mathrm{Sr}$} & \multirow{2}{*}{$u_{m}=\frac{S r}{\sqrt{n}}$} & \multirow{2}{*}{$u_{\Delta}=\sqrt{u_{m}^{2}+u_{C R M}^{2}}$} & \multirow{2}{*}{$\mathrm{U}_{\Delta}=\mathrm{k} \cdot \mathrm{u}_{\Delta}$} & \multirow[t]{2}{*}{$\Delta_{\mathrm{m}}=\left|\mathrm{C}_{\mathrm{m}}-\mathrm{C}_{\mathrm{CRM}}\right|$} & \multirow{2}{*}{$\begin{array}{l}\text { Estimated } \\
\text { enforcement }^{\text {enel }} \\
\text { level }^{\mathrm{a}} \\
C_{\mathrm{m}}-U_{\Delta}\end{array}$} \\
\hline & $R(1)$ & $R(2)$ & Mean $\%\left(C_{m}\right)$ & & & & & & \\
\hline 3 & 0.2385 & 0.1545 & 0.1965 & 0.059397 & 0.0424 & 1.5255 & 3.051 & 0.7035 & -2.855 \\
\hline 6 & 1.2499 & 0.9262 & 1.08805 & 0.22889 & 0.163 & 1.533 & 3.067 & 0.18805 & -1.979 \\
\hline 7 & 0.1492 & 0.1959 & 0.17255 & 0.033022 & 0.024 & 1.525 & 3.05 & 0.72745 & -2.877 \\
\hline 8 & 0.1477 & 0.1275 & 0.1376 & 0.014284 & 0.01 & 1.525 & 3.05 & 0.7624 & -2.912 \\
\hline 9 & 3.1444 & 4.2174 & 3.6809 & 0.758726 & 0.542 & 1.618 & 3.237 & 2.789 & 0.444 \\
\hline 12 & 0.0807 & 0.0888 & 0.08475 & 0.005728 & 0.004 & 1.525 & 3.049 & 0.81525 & -2.964 \\
\hline 13 & 1.937 & 1.903 & 1.92 & 0.024042 & 0.017 & 1.525 & 3.05 & 1.02 & -1.13 \\
\hline 16 & 0.2349 & 0.6506 & 0.44275 & 0.293944 & 0.20996 & 1.539 & 3.078 & 0.2494 & -2.635 \\
\hline 19 & 1.481 & 1.393 & 1.437 & 0.062225 & 0.045 & 1.526 & 3.051 & 0.537 & -1.614 \\
\hline 22 & 0.2304 & 0.2469 & 0.23865 & 0.011667 & 0.008 & 1.525 & 3.05 & 0.66135 & -2.811 \\
\hline 23 & 0.4035 & 0.2364 & 0.31995 & 0.118158 & 0.008 & 1.527 & 3.055 & 0.58005 & -2.735 \\
\hline 24 & 0.34 & 0.2724 & 0.3062 & 0.047800 & 0.03414 & 1.525 & 3.05 & 0.5938 & -2.744 \\
\hline 25 & 0.3579 & 0.3737 & 0.3658 & 0.011172 & 0.008 & 1.525 & 3.05 & 0.5342 & -2.684 \\
\hline 27 & 0.1533 & 0.1296 & 0.14145 & 0.016758 & 0.012 & 1.525 & 3.05 & 0.7704 & -2.909 \\
\hline 30 & 0.1985 & 0.2271 & 0.2128 & 0.020223 & 0.0144 & 1.535 & 3.069 & 0.6872 & -2.856 \\
\hline 31 & 0.2244 & 0.9168 & 0.5706 & 0.489601 & 0.3497 & 1.565 & 3.129 & 0.3294 & -2.558 \\
\hline 32 & 0.7136 & 0.9494 & 0.8315 & 0.166736 & 0.119 & 1.529 & 3.059 & 0.0685 & -2.228 \\
\hline 35 & 2.4518 & 3.45 & 2.9509 & 0.705834 & 0.50417 & 1.606 & 3.212 & 2.0509 & -0.261 \\
\hline
\end{tabular}

a Maximum concentration stipulated in EU is $0.9 \%, \mathrm{R}(1)$ is reaction 1, R (2) is reaction 2. $u_{\mathrm{m}}$; uncertainty of measurement results, Sr; standard deviation of repeatability, $n$; number of independent measurement results, $u_{\Delta}$; combined uncertainty of results and certified value, $u_{C R M}^{2}$ is uncertainty of the certified value. $k$; coverage factor equal to 2 
investigated plant samples also, confirmed the presence of genetic modifications in these samples.

To guarantee traceability of the GMOs, several strategies have been developed to detect GMOs in food/ feed samples by using different technologies. In most cases, GMO screening approaches also apply quantitative methods for detecting the presence of GM material in food and feed samples (Barbau-Piednoir et al. 2014). Many countries have imposed different biosafety laws (De Jong 2010) and GMOs labeling policies with a threshold of tolerance varying between 0 and $5 \%$ which are controlled by their competent authorities (Kamle and Ali 2013).

In the present work the standard curve approach using the Fluka certified reference material (Fluka CRM) was chosen for GMO quantification. This approach is based on absolute quantification rather than relative quantification approach (Weighardt et al. 2004) which based on the use of reference gene for normalization.

A series of parameters has to be considered to validate and verify the accuracy and the performance characteristics of the quantification method applied. One of these parameters is the squared correlation coefficient $\left(R^{2}\right)$ of the constructed standard curve. For a well-optimized reaction the $R^{2}$ value should be close to 1 and greater than 0.98 (Nolan et al. 2013). In our case $R^{2}$ value was 0.999. The dynamic range of concentrations; over which the method performed in a linear manner, is also another important performance characteristic parameter. In the present work the dynamic range of the standard curve showed a linear increase from 0.49 to $4.87 \%$. It is worthy of note here that the dynamic range of concentrations should not exceed five times the permissible concentration $(0.9 \%)$ of genetic modification (Del Gaudio et al. 2012).

Figure 5 showed that $92 \%$ reaction efficiency of the constructed standard curve indicating high efficiency and repeatability of the method employed as predicted from the line of best fit (slope) for the standard curve $(-3.526)$ in the present work. It has been reported that when a tenfold serial dilution is performed, the amplification plots for each dilution should be 3.3 cycles apart. In our case (Table 4) the amplification plots ranged from 2.26 to 3.56 cycles $(\mathrm{Ct})$ apart. This difference in assay performance could be a result of using different dilutions $(0.5$, 2 , and $5 \%$ ) for the construction of standard curve in the present work or as suggested previously by Nolan et al. (2013), that it could even be related to different syntheses of the primer pair. Others (Morisset et al. 2009) reported that this difference could also be due to mismatches in the inserted sequences that have arisen during plant crossing.
Further and according to trueness the method applied here showed no bias (Table 5), since the absolute difference $\left(\Delta_{\mathrm{m}}\right)$ between mean measured values $\left(C_{\mathrm{m}}\right)$ and certified value $\left(C_{\mathrm{CRM}}\right)$ were smaller than expanded uncertainty $\left(U_{\Delta}\right)$ of difference between result and certified value (Trapmann et al. 2014).

Additionally, Table 5 presented along with the calculation of measurement uncertainty (MU), the estimated enforcement level for each plant samples to ensure compliance with the EU $0.9 \%$ legislation. The calculated difference between the reported GM concentrations $\left(C_{\mathrm{m}}\right)$ and the expanded uncertainty $\left(U_{\Delta}\right)$ value for all samples did not exceed the permissible concentration threshold (0.9\%). Since it is not easy to avoid contamination during storage or transport of GM crops, these results indicated that the tested plant crops were considered not violating the European legislation for GMOs labeling. It also reflects the sensitivity of this approach to detect even traces of GM content in DNA of plant samples.

The validation study necessitates covering all the steps in the method to ensure evaluation of all parameters that may influence the result. One of the important parameters related to method validation as proposed by HolestJensen and Berdal (2004) is validation of DNA extraction procedures from different sample matrixes. It is well known that isolation and purification of DNA is a crucial step in DNA molecular techniques used in plant studies for the assessment of food safety (Sönmezoğlu and Keskin 2015), especially with the increase of the global cultivation area of genetically modified (GM) crops. For reliable results extraction of the DNA from all tested plant samples was performed, in the present work applying the same DNA extraction protocol to avoid any possible different composition or substances that may affect the efficiency of the PCR assays. This protocol is a modified CTAB-based method specially developed in our laboratory (Aboul-Maaty and Oraby 2019) for isolation of high quality and purity DNA from different plant orders.

\section{Conclusions}

The present work was mainly, conducted in the context of building capacities for detection and quantification of genetically modified (GM) crops applying exploratory and confirmatory molecular approaches. The results fully demonstrated the reproducibility, sensitivity / specificity of the adopted approaches for detection and quantification of even traces of GMO contents.

Applying measurement uncertainty (MU) procedures presented in this work will help decision makers to ensure compliance with International Legislation and Regulations. This in its turn will facilitate and enhance trading with countries having compelling labeling regulations. 


\begin{abstract}
Abbreviations
ARM: Antibiotic resistance marker; nptll: Neomycin phosphotransferase; DNA: Deoxyribonucleic Acid; aadA: Aminoglycoside 3" adenyl-transferase; aphIV: Hygromycin phosphotransferase; PCR: Polymerase chain reaction; GMOs: Genetically modified organisms; RT-PCR: Reverse transcription polymerase chain reaction; MU: Measurement uncertainty; C-PCR: Conventional polymerase chain reaction; P-35S: Cauliflower mosaic virus promoter; CRM: Certified reference material; dNTP: Deoxyribonucleotide triphosphate; CTAB: Cetyltrimethylammonium bromide; Ct: Threshold cycle; SYBR green: Synergy brands; $T_{m}$ : Melting temperatures; $L O Q$ : Limit of quantification; $U_{\Delta}$ : Expanded uncertainty; $\Delta_{\mathrm{m}}$ : Absolute difference; $C_{\mathrm{m}}$ : Mean measured values; $C_{\mathrm{CRM}}$ : Certified value.
\end{abstract}

\section{Acknowledgements}

Not applicable.

\section{Authors' information}

All authors are working at the Cell Biology Department, Genetic Engineering and Biotechnology Research Division, National Research Centre, Egypt.

\section{Authors' contributions}

HO made substantial contributions to conception, planning of the work, analysis and interpretation of results. Also involved in, drafting the manuscript and revising it critically for important intellectual content; as well as given final approval of the version to be published. NA-M made substantial contributions to conception and design of the work, involved in conducting the practical section of the work, and the measurement uncertainty statistical analysis. Also involved in, drafting the manuscript; as well as given final approval of the version to be published. HA-S involved in conducting the practical section of the work. Partially involved in, conducting the measurement uncertainty statistical analysis; as well as given final approval of the version to be published. Each author has participated sufficiently in the work to take public responsibility for appropriate portions of the content; and agreed to be accountable for all aspects of the work in ensuring that questions related to the accuracy or integrity of any part of the work are appropriately investigated and resolved. The authors have participated sufficiently in this work. All authors have read and approved the final manuscript.

\section{Funding}

The authors declare that this work was funded by the National Research Centre in Egypt (the 11th Research Project Plan, 2016-2019, Project ID: 1 1040201).

\section{Availability of data and materials}

Authors declare that all data generated or analyzed during this study are included in this article.

\section{Declarations}

Ethics approval and consent to participate

Not applicable.

\section{Consent for publication}

Not applicable.

\section{Competing interests}

The authors declare that they have no competing interests.

Received: 4 June 2021 Accepted: 6 November 2021

Published online: 18 November 2021

\section{References}

Aboul-Maaty NAF, Oraby HAS (2019) Extraction of high-quality genomic DNA from different plant orders applying a modified CTAB-based method. Bull Natl Res Cent 43:1-25

Adugna A, Mesfin T (2008) Detection and quantification of genetically engineered crops. J Sat Agric 6
Anklam E, Gadani F, Heinze P, Pijnenburg H, Van den Eede G (2001) Analytical methods for detection and determination of genetically modified organisms in agricultural crops and plant-derived food products. Eur Food Res Technol 214:3-26. https://doi.org/10.1007/s002170100415

Ballester A, Cervera M, Pena L (2008) Evaluation of selection strategies alternative to nptll in genetic transformation of citrus. Plant Cell Rep. 27:1005-1015

Barbau-Piednoir E, Stragier P, Roosens N, Mazzara M, Savini C, Van den Eede G et al (2014) Inter-laboratory testing of GMO detection by combinatory SYBR ${ }^{\circledR}$ Green PCR screening (CoSYPS). Food Anal Methods 7:1719-1728. https://doi.org/10.1007/s12161-014-9837-3

Cankar K, Chauvensy-Ancel V, Fortabat MN, Gruden K, Kobilinsky A, Zel J et al (2008) Detection of nonauthorized genetically modified organisms using differentialquantitative polymerase chain reaction: application to 355 in maize. Anal Bioch 376:189-199

Day A (2003) Antibiotic resistance genes in transgenic plants: their origins, undesirability and technologies for their elimination from genetically modified crops. In: Stewart NC (ed) Transgenic plants: current innovations and future trends. Horizon Scientific Press, Wymondham, pp 111-156

Del Gaudio S, Cirillo A, Di Bernardo G, Galderisi U, Cipollaro M (2012) Verification of real-time PNR methods for qualitative and quantitative testing of genetically modified organisms. J Food Qual 35:42-447

De Jong TJ (2010) General surveillance of genetically modified plants in the EC and the need for controls. J Consum Prot Food s 5:181-183

Duijn GV, Biert RV, Bleeker-Marcelis H, Peppelman H (1999) Hessing M Detection methods for genetically modified crops. Food Control 10:375-378

Farrar JS, Wittwer CT (2017) High-resolution melting curve analysis for molecular diagnostics. In: Molecular diagnostics. Academic Press, pp 79-102

Hemmer W (1997) Foods derived from genetically modified organisms and detection methods. BATS-Report 2/97, Basel, Switzerland. www.bats.ch/ abstr/297intro.htm

Hollingshead S, Vapnek D (1985) Nucleotide sequence analysis of a gene encoding a streptomycin/spectinomycinadenyltransferase. Plasmid 13:17-30. https://doi.org/10.1016/0147-619X(85)90052-6

Holst-Jensen A, Berdal KG (2004) The modular analytical procedure and validation approach and the units of measurement for genetically modified materials in foods and feeds. J AOAC Int 87:927-936

James C (1999) Preview: global status of commercialised transgenic crops: 1999. In: ISAAA briefs no 12. ISAAA, Ithaca, New York

Kamle S, Ali S (2013) Genetically modified crops: detection strategies and biosafety issues. Gene 522:123-132. https://doi.org/10.1016/j.gene.2013. 03.107

Kok EJ, Scholten IM, Angeline Van Hoef AM, Aarts HJ (2000) Detection of genetically modified DNA in food. Food information newsletter, Netherlands. http://www.ifis.org/forum/June2000/GMDetection.htm

Kumar S, Dhingra A, Daniell H (2004) Stable transformation of the cotton plastid genome and maternal inheritance of transgenes. Plant Mol Biol 56:203-216. https://doi.org/10.1007/s11103-004-2907-y

Li X, Wu Y, Li J, Li Y, Long L, Li F, Wu G (2015) Development and validation of A 48-target analytical method for high-throughput monitoring of genetically modified organisms. Sci Rep 5:7616

Mafra I, Silva SA, Moreira EJMO, da Silva CSF, Beatriz M, Oliveira PP (2008) Comparative study of DNA extraction methods for soybean derived food products. Food Control 19:1183-1190. https://doi.org/10.1016/j.foodcont. 2008.01.004

Mathur V, Javid L, Kulshrestha S, Mandal A, Reddy AA (2017) World cultivation of genetically modified crops: opportunities and risks. Sustain Agric Rev 25:45-87

Miki B, McHugh S (2004) Selectable marker genes in transgenic plants: applications, Iternatives and biosafety. J Biotechnol 107:193-232. https://doi.org/ 10.1016/j.jbiotec.2003.10.011

Morisset D, Demsar T, Gruden K (2009) Detection of genetically modified organisms. Closing the gaps. Nat Biotechnol 27:700-701

Nolan T, Huggett J, Sanchez E (2013) Good practice guide for the application of quantitative PCR (qPCR). LGC

Oraby HAS, Hassan AA, AbouMossallam AA (2005) Screening food products for the presence of CaMV 355 promoter and NOS $3^{\prime}$ terminator. J Sci Food Agric 85:1974-1980. https://doi.org/10.1002/jsfa.2201

Oraby HAS, Kandil MM, Hassan AA, Al-Sharawi HA (2014) Addressing the issue of horizontal gene transfer from a diet containing genetically modified 
components into rat tissues. Afr J Biotechnol 3:4410-4418. https://doi. org/10.5897/AJB2014.14088

Salisu IB, Shahid AA, Yaqoob A, Ali Q, Bajwa KS, Rao AQ, Husain T (2017) Molecular approaches for high throughput detection and quantification of genetically modified crops: a review. Front Plant Sci 8:1670

Sönmezoğlu ÖA, Keskin H (2015) Determination of genetically modified corn and soy in processed food products. J Appl Biol Biotechnol 3:32-37. https://doi.org/10.7324/JABB.2015.3307

Surekha CH, Beena MR, Arundhati A, Singh PK, Tuli R, Dutta-Gupta A et al (2005) Agrobacterium-mediated genetic transformation of pigeon pea (Cajanus cajan (L.) Millsp.) using embryonal segments and development of transgenic plants for resistance against Spodoptera. J Plant Sci 169:1074-1080

Tabatabaei I, Ruf S, Bock RA (2017) Bifunctional aminoglycoside cetyltransferase/phosphotransferase conferring tobramycin resistance provides an efficient selectable marker for plastid transformation. Plant Mol Bio 93:269-281. https://doi.org/10.1007/s11103-016-0560-x

Trapmann S, Burns M, Broll H, Macarthur R, Wood R, Zel J (2009) Guidance document on measurement uncertainty for GMO testing laboratories 2nd (ed) http://irmm.jrc.ec.europa.eu/html/reference_materials_catal ogue/user_support/EUR22756EN.pdf13. Accessed 31 May 2010

Trapmann S, Charles Delobel C, Corbisier P, Hougs L, Philipp P, Sandberg MM (2014) European technical guidance document for the flexible scope accreditation of laboratories quantifying GMOs. 2nd version. https://crm. jrc.ec.europa.eu/graphics/cms_docs/accreditation_scope_gmo.pdf+\& $\mathrm{cd}=2 \& \mathrm{hl}=\mathrm{en} \& \mathrm{ct}=\mathrm{clnk \& gl=eg}$

Vidhya SS, Gowda PH, Yogendra KN, Ningaraju TM, Salome T (2012) Detection of genetically modified cotton seeds using PCR and real-time PCR. Indian J Biotechnol 11:176-181

Weighardt F, Barbati C, Paoletti M, Querci M, Kay S, De Beuckeleer M, Van den Eede G (2004) Real-time polymerase chain reaction-based approach for quantification of the pat gene in the T25 Zea mays event. J AOAC Int 87:1342-1355

Wu Y, Wang Y, Li J, Li W, Zhang L, Li Y et al (2014) Development of a general method for detection and quantification of the P35S promoter based on assessment of existing methods. Sci Rep 4:7358. https://doi.org/10.1038/ srep07358

Zenga H, Wanga J, Jiaa J, Wua G, Yanga Q, Liub X, Tanga X (2021) Development of a lateral flow test strip for simultaneous detection of BTCry1Ab, BT-Cry1AC and CP4 EPSPS proteins in genetically modified crops. Food Chem 335:127627

\section{Publisher's Note}

Springer Nature remains neutral with regard to jurisdictional claims in published maps and institutional affiliations.

\section{Submit your manuscript to a SpringerOpen ${ }^{\odot}$ journal and benefit from:}

- Convenient online submission

- Rigorous peer review

- Open access: articles freely available online

- High visibility within the field

- Retaining the copyright to your article

Submit your next manuscript at $\boldsymbol{\nabla}$ springeropen.com 